Témoigner Témoigner. Entre histoire et mémoire

Getuigen Revue pluridisciplinaire de la Fondation Auschwitz

Violences radicales en scène

\title{
Interview met Guy Cassiers
}

Deconstructie van het verleden, een nieuwe kijk op de geschiedenis

Revisiter l'Histoire en déconstruisant les événements. Entretien avec

Guy Cassiers

\section{Guy Cassiers et Edwige Perrot}

Traducteur : Anneleen Spiessens

\section{OpenEdition}

\section{Journals}

Édition électronique

URL : https://journals.openedition.org/temoigner/3293

DOI : $10.4000 /$ temoigner.3293

ISSN : 2506-6390

Cet article est une traduction de :

Revisiter l'Histoire en déconstruisant les événements - URL : https://journals.openedition.org/ temoigner/3279 [fr]

\section{Éditeur :}

Éditions du Centre d'études et de documentation Mémoire d'Auschwitz, Éditions Kimé

\section{Édition imprimée}

Date de publication : 1 octobre 2015

Pagination : 59-63

ISSN : 2031-4183

\section{Référence électronique}

Guy Cassiers en Edwige Perrot, «Interview met Guy Cassiers», Témoigner. Entre histoire et mémoire [Online], 121 | 2015, Online op 01 octobre 2016, geraadpleegd op 04 février 2022. URL: http:// journals.openedition.org/temoigner/3293 ; DOI: https://doi.org/10.4000/temoigner.3293 


\section{Guy Cassiers}

$\rightarrow$ Interview door

Edwige Perrot
Politiek geweld is een terugkerend thema in uw werk: Bezonken rood, Mefisto for Ever, Wolfskers, Atropa, Duister hart, binnenkort De welwillenden. Waarom moet dat onderwerp op het toneel behandeld worden?

Guy Cassiers: Het meest sprekende voorbeeld staat zelfs niet in uw lijst: twintig jaar geleden bracht ik Time's Arrow van Martin Amis. De manier waarop Amis het verhaal vertelt is erg relevant voor de thematiek van macht en herinnering, het belang van je geschiedenis te kennen en die kennis vandaag te gebruiken. Time's Arrow vertelt het verhaal van een man, maar achterstevoren. Het begint met zijn dood, op het moment dat zijn bewustzijn weer wakker schiet door de elektroshocks die de artsen hem toedienen. Vanaf dan gaat het personage terug in de geschiedenis, stap voor stap, moment voor moment, alsof de gebeurtenissen uit zijn leven zich één na één ontspinnen tot in het kleinste detail. Het bewustzijn, dat niet begrijpt wat er gebeurt en waartoe dat allemaal leidt, tracht het proces te vatten waarin het is verstrikt geraakt. Het meest treffende aspect van het boek, voor mij althans, en van het stuk dat we ervan hebben gemaakt, is het feit dat dit leven pas zin krijgt tijdens de Tweede Wereldoorlog, wanneer het personage arts is in Auschwitz. Net als in de rest van het boek wordt ook deze fase van achteren naar voren verteld: mannen en vrouwen verrijzen uit de as, de arts geeft hen haren en gouden tanden. En op dat moment beseft het bewustzijn dat de terugkeer in het verleden een doel heeft, dat het betekenis geeft aan de dingen. Ik vond het indrukwekkend om de geschiedenis van de Tweede Wereldoorlog te herontdekken vanuit het bijzondere perspectief van deze vertelling. Door terug te gaan in de tijd en de logische opeenvolging van gebeurtenissen te deconstrueren, wordt het mogelijk om niet alleen de feiten uit het verleden maar ook hun betekenis, hun zin, op een meer directe manier te benaderen. En om eruit te leren. Het procedé om de loop van de geschiedenis om te keren, van gevolg naar oorzaak, creëert een emotionele intensiteit die de realiteit van de dingen naar boven brengt en inzicht biedt in de manier waarop ze zijn verlopen, in hun mechanica, om het zo te zeggen. Dat maakt mij als mens verantwoordelijk om ervoor te zorgen dat die mechanismen nooit meer in gang worden gezet. We moeten waakzaam blijven. Iedereen zegt: 'Kijk, dat ligt in het verleden, het zal zich niet meer herhalen...' Ik geloof dat alles opnieuw kan gebeuren. 
Deconstructie van het verleden, een nieuwe kijk op de geschiedenis (vervolg)

\section{THEATER ALS BASTION TEGEN HET VERGETEN}

Het toneel lijkt voor u een plaats van herinnering... maar het is tegelijkertijd een plaats die zich leent voor fictie.

G.C.: Inderdaad, ik vind het zeer belangrijk om de geschiedenis in herinnering te houden. Het belangrijkste is niet alleen om te weten wat er is gebeurd, maar om bij de toeschouwer een persoonlijke emotie op te roepen en zo een band te scheppen met dat verleden. We moeten onze band met de geschiedenis onderhouden. Onze verantwoordelijkheid opnemen door te herinneren, en die herinnering in te zetten in de toekomst. De geschiedenis draag je niet zomaar met je mee, je trekt er lessen uit voor later. Dat is precies waar theater van nut kan zijn, waar theater ons kan helpen: via de weg van fictie slaagt ze erin om historische feiten een intense emotionele lading te geven. Ik heb het idee dat we tegenwoordig voortdurend blootgesteld worden aan een overvloed aan beelden die ons de gruwel, de vernietiging, het lijden overal ter wereld tonen. Maar dat is het probleem met beelden: hoe vaker je ze ziet, hoe meer je eraan went. We zijn het zo gewoon om dingen te zien die de werkelijkheid lijken te overstijgen, dat we er uiteindelijk blind voor worden, en gaan vergeten. Kunst belet ons om te vergeten.

\section{OP ZOEK NAAR DE MECHANISMEN VAN HET GEWELD}

De geschiedenis, de macht en de gruwelijkheden die daarmee gepaard gaan, worden in uw stukken belichaamd door personages die vaak wreed zijn - die zo zijn geworden of het worden op de scène: een jonge moordenaar in Rotjoch, een slachtoffer van de Japanse concentratiekampen in Bezonken rood, dictators in Wolfskers, een getuige van de koloniale verschrikkingen in Duister hart, en binnenkort een intellectueel en beul in De welwillenden. Waarom is het voor u essentieel om het geweld door die verschillende prisma's te belichten?

G.C.: Aan het begin van Bezonken rood zien we een compleet geïsoleerde man. Hij wil niet communiceren en beweert dat zijn leven afgelopen is. Wat het boek zo subliem maakt, en wat we ook met het stuk probeerden te bereiken, is dat je je aanvankelijk verzet tegen het personage. Je wil je er in geen geval mee identificeren. Maar in de loop van zijn getuigenis ga je je schuldig voelen over die weerstand, over je snelle en makkelijke oordeel. Want hoe onsympathiek hij ook mag lijken, eens de man heeft verteld wat hij heeft meegemaakt in zijn jeugd, ga je zijn gedrag beter begrijpen. Niet dat het zijn fouten goedpraat, maar we vragen ons als publiek wel af wat we in zijn plaats hadden gedaan, hadden we zoiets meegemaakt. Zouden we kunnen worden zoals hij, in die situatie?

Een gelijkaardig proces ligt aan de basis van Patrick McCabes Butcher Boy (Rotjoch in de toneelbewerking). Dat gaat over een geïsoleerd kind uit een kansarm sociaal en familiaal milieu dat de wereld om hem heen niet helemaal vat. De jongen werkt in een slachthuis en ziet na een tijd het verschil niet meer tussen dieren en mensen. Uiteindelijk slaat hij aan het moorden. Hij heeft nu eenmaal nooit 
geleerd om zijn gevoelens en gedachten te ontwikkelen. We maakten van het boek een theatermonoloog om te kunnen focussen op de interactie tussen het kind en de wereld, om te laten zien hoe de jongen de wereld waarneemt en hoe hij de anderen ervaart. De stem van de overige personages was aanwezig op het podium via videoprojecties van hun teksten. De toeschouwers konden die zelf lezen en aan de hand van de reactie van de acteur begrepen ze welke impact de woorden hadden op het kind, kregen ze inzicht in zijn leefwereld en zijn gedrag. We wilden in de eerste plaats de afstand benadrukken tussen dit kind en

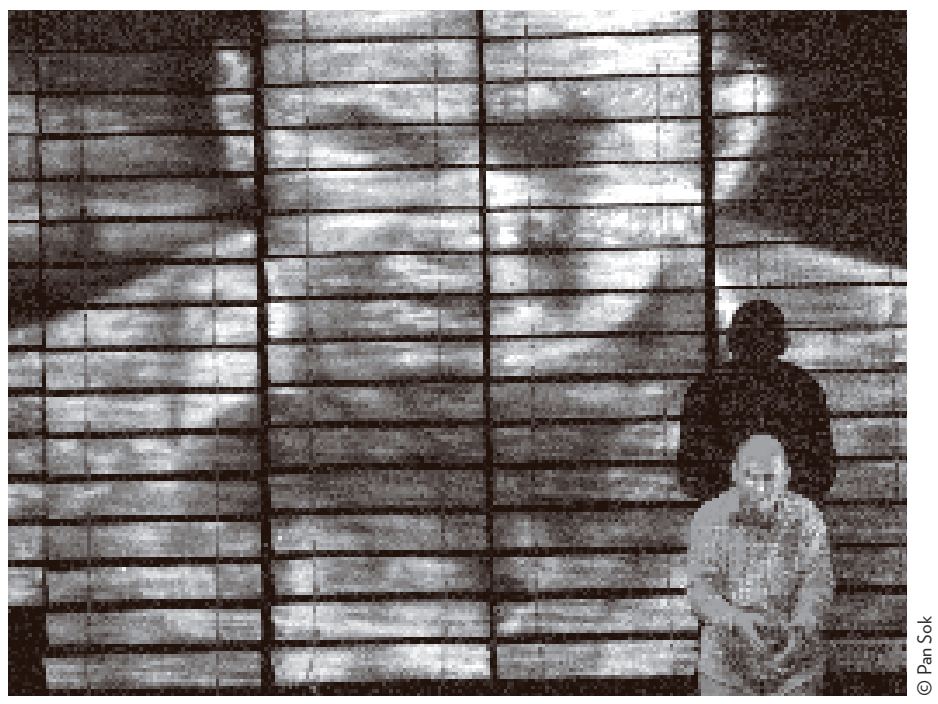
de wereld. Om het personage te doorgronden, maar vooral om te tonen hoe iemand een moordenaar kan worden, om de mechanismen van dat proces bloot te leggen. Daarom breng ik dus wrede personages op het podium - machtige personages of juist personages die zich in de marge van de samenleving bevinden, mensen die verloren zijn, hun plaats niet vinden en onmenselijke daden plegen. Begrijpen hoe zoiets in z'n werk gaat, is volgens mij cruciaal om te vermijden dat het opnieuw gebeurt.

\section{HET DUISTERE IN IEDER VAN ONS}

In Duister hart zien we een personage dat een man gaat opzoeken om hem hulp te bieden. De tocht die hij onderneemt, lijkt echter steeds meer op een reis naar de afgrond, in die mate dat hij zelf ook begint over te hellen naar het kwade. Op dat moment beseffen we dat er in ieder van ons een soort neiging tot gruwelijkheid schuilt. Hetzelfde geldt trouwens voor De welwillenden. Het personage erkent dat hij het kwade belichaamt, dat hij alles heeft gedaan wat een mens nooit zou mogen doen. Maar hij stelt ons ook de vraag: in dezelfde situatie, hadden jullie het anders aangepakt? Aanvankelijk zeggen we stellig: dat zou ons nooit zijn overkomen. Maar vreemd genoeg, hoe verder we in het boek lezen, hoe meer die zekerheden gaan wankelen. Hoe meer we gaan betwijfelen of we het wel beter hadden gedaan en ons gaan afvragen of we niet net als hem zouden hebben gehandeld. Het is belangrijk om je bewust te zijn van het gevaar dat die dingen opnieuw kunnen gebeuren.

Gebruikt u daarom videobeelden, om in de geest van het personage te kruipen en diens interne monoloog weer te geven?

G.C.: Inderdaad. We moeten situaties en personages op het toneel brengen, maar in feite zijn de gedachten het allerbelangrijkst. Dáár draait het om. Over het gedrag van de mens, en diens relatie tot taal. Hoe beïnvloedt taal het gedrag? Macht haal je niet enkel uit wat je zegt, maar ligt grotendeels in de gave om het fraai uit te leggen. 
Deconstructie van het verleden, een nieuwe kijk op de geschiedenis (vervolg)
(1) Susan Sontag, Regarding the Pain of Others, Penguin Books, 2004, 106.
Zo win je mensen voor je. We worden voortdurend verleid door de vormelijke kracht van de taal, de inhoud komt pas later.

Taal en tekst krijgen steeds een wezenlijke plaats in uw stukken, net als videoprojecties en beelden...

G.C.: Het wezen van theater is voor mij de taal zelf. Taal moet een belangrijk aandeel krijgen: we moeten stilstaan bij de manier waarop we haar gebruiken, en waarop ze gebruikt wordt. Beelden kunnen een extreem grote impact hebben op extreem korte tijd, maar je raakt er even makkelijk de voeling mee kwijt. Taal werkt trager naar mijn idee, we verteren haar op een andere manier. Louter lichamelijk gezien moet dat zich op een andere plek in het brein afspelen. Ik ben het helemaal eens met wat Susan Sontag schrijft in een van haar essays: 'There's nothing wrong with standing back and thinking. To paraphrase several sages: "Nobody can think and hit someone at the same time."' Met andere woorden, denken kan ons beschermen tegen onze eigen wreedheid. Het klinkt eenvoudig, maar volgens mij is dat de essentie: je moet mensen doen nadenken, je moet het debat voeden. Oorlog en geweld ontstaan wanneer de taal het begeeft, wanneer zij faalt. Daarom vind ik het belangrijk om te werken aan de kwaliteit van de taal en van de redenering.

\section{TAAL DIE HET ONVERDEDIGBARE VERDEDIGT}

In een aantal van uw stukken onderzoekt u het verband tussen macht en taal, als reactie op de opkomst van populistische ideeën in Vlaanderen en Europa. Hoe ziet u die relatie tussen macht, geweld en taal precies?

G.C.: Dat was inderdaad het geval voor Mefisto for Ever. We werken op dezelfde manier voor De welwillenden en Le sec et l'humide van Jonathan Littell. We willen aantonen hoe de fascistoïde identiteit deels door de taal wordt gegenereerd, en hoe ons gedrag erdoor wordt beïnvloed. Littell bestudeert dat proces in Le sec et l'humide, waar hij een analyse voorstelt van de geschriften van Léon Degrelle aan de hand van het sociologische model van Klaus Theweleit. Dat doet hij ook in De welwillenden, al zegt hij het daar niet met zoveel woorden. Je leest hoe de uitroeiing van de Joden tijdens de Tweede Wereldoorlog verklaard en zelfs verantwoord kon worden via de taal. Het is werkelijk een verbijsterend boek omdat het haarfijn beschrijft hoe de moord telkens op een nieuwe manier wordt gerechtvaardigd. De manipulatie van taal laat toe het onverdedigbare te verdedigen, precies door afstand te scheppen tussen mensen en hun gevoelens. Dan zie je hoe groot de macht van taal kan zijn, hoe we ons erachter verschuilen om dingen te doen waarvan we weten dat ze fout zijn, of om ons af te keren van mensen voor wie we eigenlijk verantwoordelijk zijn. Het is via de taal dat de verantwoordelijken hun daden ontkenden, terwijl ze goed genoeg wisten dat ze verkeerd waren. Ik zie veel parallellen tussen onze tijd en het verleden zoals Littell dat met veel zin voor detail beschrijft in De welwillenden. Ik heb het dan niet over de gebeurtenissen op zich, maar over de manier waarop we ons gedragen en de taal gebruiken om onze individuele verantwoordelijkheid af te wijzen. 


\section{EXTREEM GEWELD OP/IN SCÈNE}

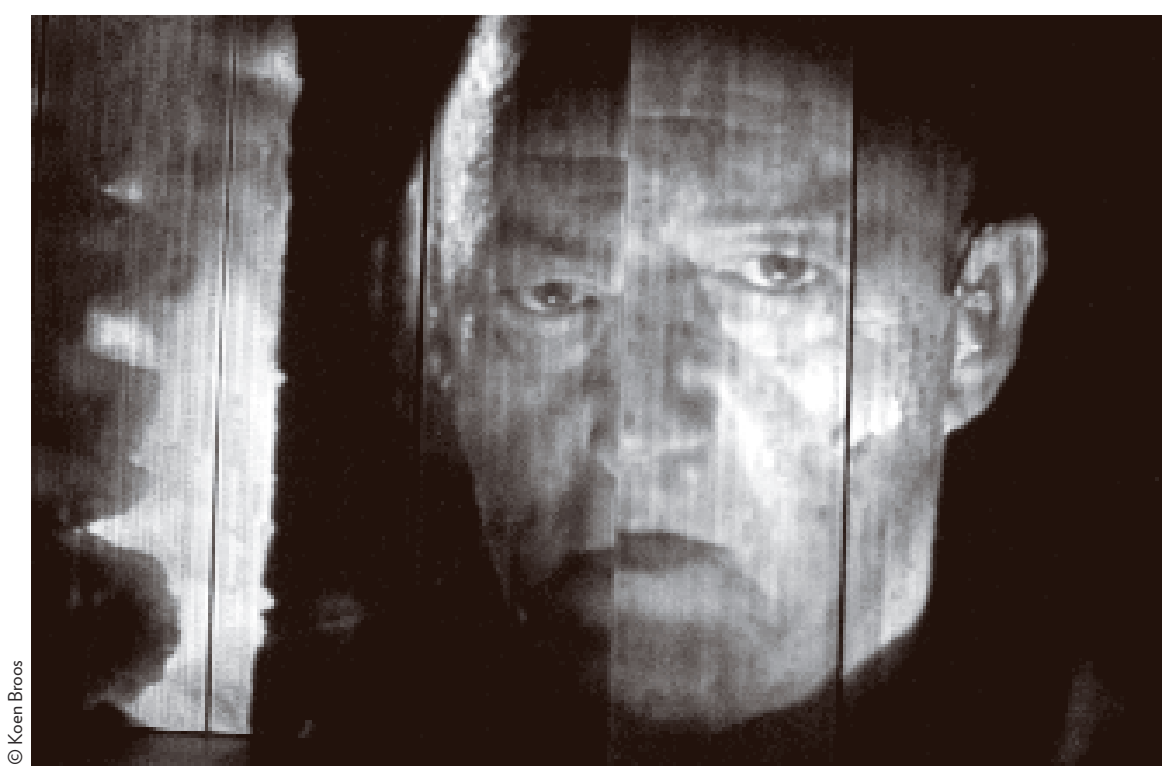

\section{THEATER OM DE INDIVIDUELE VERANTWOORDELIJKHEID AAN TE SPREKEN}

Uit uw visie op theater zouden we kunnen opmaken dat u politiek theater maakt. Ziet u dat ook zo?

G.C.: De rol van theater bestaat er volgens mij in om de toeschouwers hun individuele verantwoordelijkheid te helpen aanvaarden. Ik maak geen politiek theater, in die zin dat ik de mensen mijn persoonlijke ideeën over een bepaald onderwerp niet wil opdringen. Het is juist fundamenteel dat zij een eigen mening vormen, een eigen gedachtegang ontwikkelen en zich bewust worden van hun verantwoordelijkheid als individu. Daarom probeer ik zoveel mogelijk informatie aan te reiken, zonder restrictief te werken. De kracht van theater bestaat erin dat zij middelen kan aanreiken om zo'n talent bij de toeschouwer zelf te ontwikkelen. Het is in geen geval de bedoeling mensen te overtuigen om op een bepaalde manier te gaan denken, of om een oordeel te vellen over wat juist is en wat fout.

Theater heeft tijd nodig, en afstand. In de wereld waarin we vandaag leven is het al veel gevraagd om twee uur van je tijd uit te trekken om na te denken over een thema, zeker voor jongeren. Onze ervaring van tijd is volledig het veranderen. Theater creëert een soort van tijdbubbel en biedt ons instrumenten om anders te kijken naar de dingen die we denken te kennen. Fictie brengt ons bovendien mentaal dichter bij de realiteit. Het is immers dankzij de verbeelding, die wordt aangesproken door fictie, dat we een intieme band ontwikkelen met iets of iemand, een heel persoonlijke toegangsweg. Dat is de basis van alle theater. Dat is zijn kracht. I 